\title{
Surface ozone scenario at Pune and Delhi during the decade of 1990 s
}

\author{
Kaushar Ali ${ }^{1, *}$, S R Inamdar ${ }^{1}$, G Beig ${ }^{1}$, S Ghude ${ }^{1}$ and Sunil Peshin ${ }^{2}$ \\ ${ }^{1}$ Indian Institute of Tropical Meteorology, Pune, Dr. Homi Bhabha Road, Pashan, \\ NCL Post Office, Pune 411 008, India. \\ ${ }^{2}$ India Meteorological Department, Mausam Bhavan, Lodi Road, New Delhi 110 003, India. \\ ${ }^{*}$ Corresponding author.e-mail: kaushar@tropmet.res.in
}

\begin{abstract}
Data on surface ozone concentration compiled for a 10-year period from 1990 to 1999 for Pune and Delhi are analyzed in terms of its frequency distribution, annual trend, diurnal variation and its relation with various meteorological and chemical parameters. It is found that the surface ozone concentration range showing highest frequency of occurrence at Pune is $0-5 \mathrm{ppb}$ during winter and post-monsoon seasons and 15-20 ppb and 5-10 ppb during summer and monsoon seasons, respectively. It is $0-5 \mathrm{ppb}$ at Delhi during all the seasons. The surface ozone concentration has shown a decreasing trend at Pune during the observational period with an average rate of decrease of $1.54 \mathrm{ppb} /$ year. On the other hand, there is no trend whatsoever in the variation of surface ozone concentration at Delhi. Minimum value of surface ozone occurs before sunrise and maximum in the afternoon hours. Regression analyses of surface ozone with maximum temperature $(r=0.46$ for Pune and 0.51 for Delhi, significant at more than $0.1 \%)$ and $\mathrm{NO}_{2}$ at respective locations indicate that surface ozone at these locations is mainly produced by photochemistry. Transport mechanism is also understood to have contributed significantly to the total concentration of ozone. Inverse relationship obtained between surface ozone concentration and relative humidity indicates that major photochemical paths for removal of ozone become effective when humidity increases at these locations.
\end{abstract}

\section{Introduction}

Surface ozone is of immense societal concern due to its adverse impact on human, plants and buildings as one of the major atmospheric pollutants and also due to its implications in the global warming and the climate change as one of the green house gases. It comes into direct contact with different life-forms on the earth and displays its destructive side mainly due to its toxicity. Several studies have documented the harmful effects of surface ozone on crop production, forest growth, and human health (Reich and Lassoie 1985; Lippmann
1991). The substantial negative effects of the surface layer ozone from the direct toxicity contrast with the benefits of the additional filtering of UV$\mathrm{B}$ radiation that it provides in the stratosphere. On account of the fact that surface ozone reacts strongly with other gaseous molecules in the atmosphere, its presence in the boundary layer with high concentration level will influence the tropospheric chemistry of the atmospheric chemical species (Liu et al 1987).

Surface ozone at any location over the globe is mainly produced by photochemical mechanism which involves, initially, action of solar radiation at

Keywords. Surface ozone; frequency distribution; diurnal variation; photochemistry; relative humidity. 
wavelengths shorter than $310 \mathrm{~nm}$ on $\mathrm{O}_{3}$ molecule. Ozone then undergoes photolysis to yield singlet oxygen atom, $\mathrm{O}\left({ }^{1} \mathrm{D}\right)$, which combines with water vapour to produce hydroxyl radical $\left(\mathrm{HO}^{*}\right)$. The hydroxyl radical reacts with hydrocarbons (HCs or $\mathrm{C}_{\mathrm{n}} \mathrm{H}_{2 \mathrm{n}+2}$ ) to yield alkyl radical $\left(\mathrm{R}^{*}\right.$ or $\left.\mathrm{C}_{\mathrm{n}} \mathrm{H}_{2 \mathrm{n}+1}\right)$. Alkyl radical oxidizes to alkyl peroxy radical $\left(\mathrm{RO}_{2}^{*}\right)$ which combines with nitric oxide (NO) to produce nitrogen dioxide $\left(\mathrm{NO}_{2}\right)$ and alkoxy radical ( $\left.\mathrm{RO}^{*}\right)$. In the presence of solar radiation of wavelength less than $410 \mathrm{~nm}, \mathrm{NO}_{2}$ undergoes photolysis to produce oxygen atom $(\mathrm{O})$. This oxygen atom combines with oxygen molecule $\left(\mathrm{O}_{2}\right)$ to produce ozone molecule $\left(\mathrm{O}_{3}\right)$.

The alkoxy radical formed in this process is oxidized to alkanal (RCHO) which further undergoes photolysis by solar radiation at wavelength smaller than $330 \mathrm{~nm}$ to generate formyl radical $\left(\mathrm{HCO}^{*}\right)$. The formyl radical then oxidizes and yields carbon monoxide (CO) and hydroperoxy radical $\left(\mathrm{HO}_{2}\right)^{*}$. Again this peroxy radical participates in oxidizing $\mathrm{NO}$ to $\mathrm{NO}_{2}$ and finally producing $\mathrm{O}_{3}$ (kindly see Graedel and Crutzen 1993 for details). The $\mathrm{CO}$ formed in the reaction has two routes of its oxidation. One is ozone producing and the other is ozone destroying depending upon the abundance of $\mathrm{NO}_{\mathrm{x}}\left(\mathrm{NO}+\mathrm{NO}_{2}\right)$. The photochemical mechanism described above reveals that $\mathrm{CO}$, $\mathrm{NO}_{\mathrm{x}}$ and HCs (Hydocarons) gases play significant role, rather key role, in the production of surface ozone and hence, these gases are known as ozone precursors.

With the increased consumption of energy resources, particularly fossil fuel and bio-fuel, over the globe, there has been considerable increase in the emission of surface ozone precursor gases with the passage of time. Volz and Kley (1988) have pointed out that, in the northern hemisphere, the tropospheric $\mathrm{O}_{3}$ concentration has been more than doubled over the past century, which is attributed basically to the anthropogenic emissions of $\mathrm{O}_{3}$ precursor gases (Kelly et al 1984; Penkett 1984; Crutzen 1988; Kuntasal and Chang 1987).

It is well documented that temperature has direct impact on the $\mathrm{O}_{3}$ production rate (Vukovich 1994; Sillman and Samson 1995; Walcek and Yuan 1995). Basically, higher temperatures increase the emission rate of surface ozone precursors (Valente and Thornton 1993) which in turn accelerate the photochemical ozone production in the lower troposphere. However, the temperature itself may not always be the direct cause for the increase in $\mathrm{O}_{3}$ production. It may be a surrogate for other meteorological effects such as relative humidity, cloud coverage, lightning, atmospheric stability, stagnation, wind speed and solar intensity.

There have been a few observational and model studies on the surface ozone in the recent past to understand relative importance of its various source and sink mechanisms over the Indian continental and marine regions and to delineate its spatio-temporal distribution over the region (Singh et al 1997; Ali et al 2004, 2009; Beig and Ali 2006; Beig et al 2008; Lal et al 2008; Londhe et al 2008; Reddy et al 2008; Roy et al 2008; Ganguly 2009; Purkait et al 2009). However, a study of the kind investigating impact of various meteorological and chemical parameters on the production of surface ozone over the Indian region is rare (Vukovich and Sherwell 2003; Ali et al 2004; Jain et al 2005; Steiner et al 2010; Nishanth and Kumar 2011). Therefore, an attempt has been made in the present data presentation to understand preferred occurrence of surface ozone concentration level, its variation on different time scales (e.g., trend, diurnal and seasonal analyses) and the role of meteorological and chemical parameters in the photochemistry of surface ozone at two different locations of India. It may be noted that, for the seasonal analysis of surface ozone, a year has been divided, as per IMD, into four seasons, viz., winter (December-February), summer or pre-monsoon (March-May), monsoon (June-September) and post-monsoon (OctoberNovember) seasons.

\section{Observational locations}

The present study is based on the measurement of surface ozone at Pune $\left(18.58^{\circ} \mathrm{N}, 73.91^{\circ} \mathrm{E}\right)$ and Delhi $\left(28.56^{\circ} \mathrm{N}, 77.11^{\circ} \mathrm{E}\right)$. The selection of these two locations lies in the fact that the two cities record massive emission of ozone precursors like $\mathrm{NO}_{\mathrm{x}}$ and $\mathrm{CO}$, but they are climatologically very different. They differ not only in latitude but also in topography, terrain, altitude and surrounding. The climate of Pune is classified as tropical savanna, hot, and seasonally dry (usually winter). On the other hand, the climate of Delhi is influenced by its inland position and the prevalence of air of the continental type during the major part of the year. The region is variously classified as monsoon and upland savanna or dry sub-humid. So, this study is made fundamentally to understand how the climatic differences reflect in the production of ozone in the presence of high concentration of ozone precursor gases. The detailed description on both the observational locations and the climatology of the regions are given below.

\subsection{Pune}

Pune is situated at a height of $559 \mathrm{~m}$ above mean sea level. It is close to the west coast of India and 
lies to the east of the Western Ghats which run from north to south separating coastal districts from rest of the Maharashtra. The western slopes and coastal districts get very heavy monsoon rains while the rainfall drops to less than a tenth within a short distance to the east of the Ghats. Clear skies, light surface winds and very low relative humidity exist during winter. The cold season from November to February is followed by hot season lasting up to early June. This season is governed by high temperature and gusty winds. The period from early June to about the beginning of October constitutes southwest monsoon season. This period is dominated by rain and westerly airflow which brings clean marine air from the Arabian Sea. The succeeding period up to November is the transition period which is dominated by easterly airflow.

Pune is one of the highly polluted cities in India. The pollution in this city is mainly due to the vehicular emissions in the city area and also due to the emissions from major to minor industries situated at a distance of about $25 \mathrm{~km}$ from the ozone monitoring site in an area extending from northeast to northwest.

\subsection{Delhi}

Delhi is situated at an average height of $220 \mathrm{~m}$ above mean sea level. The adjoining region of Delhi is almost plain. The ground elevation starts rising in the north-east beyond $160 \mathrm{~km}$ from Delhi and rises steadily reaching the Himalayan foothills at about $280 \mathrm{~km}$ (Chatterjee et al 1993). The climate of this area clearly shows the influence of its inland position in a monsoon regime. Precipitation occurrence over the region is mainly due to seasonally influenced meso-scale to synoptic scale weather disturbances. The day temperatures, on average, are highest in May but the monthly mean temperatures are highest in June when night temperatures are also highest. The coldest month is January. The air over this region is dry for most of the year and especially so during April-June. It is only during monsoon when humidity over the region is high. Winds over Delhi are light during post-monsoon and winter months. They strengthen during summer and monsoon months. Except during monsoon months, winds are predominantly from a westerly or northwesterly direction and tend to northerly in the afternoon. Easterly and southeasterly winds are more common in the monsoon months [India Meteorological Department (IMD) 1991].

Delhi is one of the most polluted metropolitan cities in India. The pollution in this city is caused mainly by numerous industrial and vehicular activities in and around the city area.

\section{Data and methodology}

Surface ozone concentration, maximum temperature and relative humidity measured by the India Meteorological Department at Pune and Delhi during 1990-1999, and Global Ozone Monitoring Experiment (GOME) satellite derived monthly averaged tropospheric $\mathrm{NO}_{2}$ column data available for Pune and Delhi for a period from 1996 to 1999 form the dataset for the present study.

Measurement of surface ozone has been made by using standard Potassium Iodide (KI) technique (IMD Manual 1995). The technique involves drawing of ambient air through KI solution with the help of a suction pump. Two electrodes (a cathode of Platinum and an anode of Silver) connected with an external circuit are dipped in the solution. When air enters the solution, the ozone present in the air reacts with KI liberating free Iodine at the cathode according to the following reaction:

$$
2 \mathrm{KI}+\mathrm{H}_{2} \mathrm{O}+\mathrm{O}_{3} \rightarrow 2 \mathrm{KOH}+\mathrm{O}_{2}+\mathrm{I}_{2}
$$

The free Iodine liberated at the cathode is reduced to Iodide as:

$$
\mathrm{I}_{2}+2 \mathrm{e}^{-} \rightarrow 2 \mathrm{I}^{-}
$$

At the anode, the Iodine is reformed and combines with Silver $(\mathrm{Ag})$ to form Silver Iodide (AgI).

$$
\begin{gathered}
2 \mathrm{I}-2 \mathrm{e}^{-} \rightarrow \mathrm{I}_{2} \\
\mathrm{I}_{2}+2 \mathrm{Ag} \rightarrow 2 \mathrm{AgI}
\end{gathered}
$$

The AgI precipitates out of the solution and thereby prevents the reformed Iodine from recirculation. As reaction (1) indicates, every molecule of ozone liberates two Iodine atoms after reaction with the solution which in turn results in a flow of two electrons in the external circuit. These two electrons form the ozone current and absolute value of ozone is recorded by a $0-1 \mu \mathrm{A}$ strip chart recorder. The accuracy of the ozone measurements by this technique has been estimated to be $\pm 10 \%$ (Sreedharan and Tiwari 1971).

Maximum temperature has been measured with the help of a Maximum-Minimum Thermometer and relative humidity has been estimated by standard method using measurement of dry bulb and wet bulb temperatures. The $\mathrm{NO}_{2}$ data are downloaded from www.temis.nl website.

Surface ozone concentration has been measured round the clock at 2-hr interval during the period of observation. The ozone data so obtained are averaged for individual months of each year and are then used for various statistical analyses. The other supporting data are averaged as required for the present surface ozone study. 


\section{Results and discussion}

\subsection{Frequency distribution of surface ozone concentration at Pune and Delhi}

Figure 1 is a plot showing percentage frequency distribution of surface ozone concentration at Pune and Delhi for all the four seasons. The distribution is plotted in per cent of frequency by comparing one distribution with the other. However, the total number of observations made in a season is shown in the figures to enable one to quantify actual frequency of occurrence of the particular concentration range. The observed distributions for individual seasons are attempted to fit to a standard distribution. It is seen that exponential decay of first order fits well to the observed frequency distribution in winter and post-monsoon seasons at Pune and in all seasons at Delhi. The general form of equation which is found to fit is given as:

$$
Y=Y_{0}+A \exp \left(\frac{-X}{t}\right)
$$

where $Y_{0}$ is offset frequency, $A$ is amplitude and $t$ is decaying constant of the distribution.

The observed frequency distribution in summer and monsoon seasons at Pune conforms to Gaussian distribution given by:

$$
Y=Y_{0}+\frac{A}{w \sqrt{ }(\pi / 2)} \exp \frac{-2\left(X-X_{c}\right)^{2}}{w^{2}}
$$

where $Y_{0}$ is the offset frequency, $X_{c}$ is the central concentration, that is, concentration corresponding to peak frequency and $w$ is the width equivalent to twice the standard deviation of the data series. The equations relating to the fitted frequency distributions are shown in the respective figures.

The difference between frequency distributions of the surface ozone concentration in summer and monsoon seasons at Pune and those at Delhi may be the result of the climatic difference between the two locations. However, it is difficult to estimate with the present dataset the physical condition of the atmosphere which is really

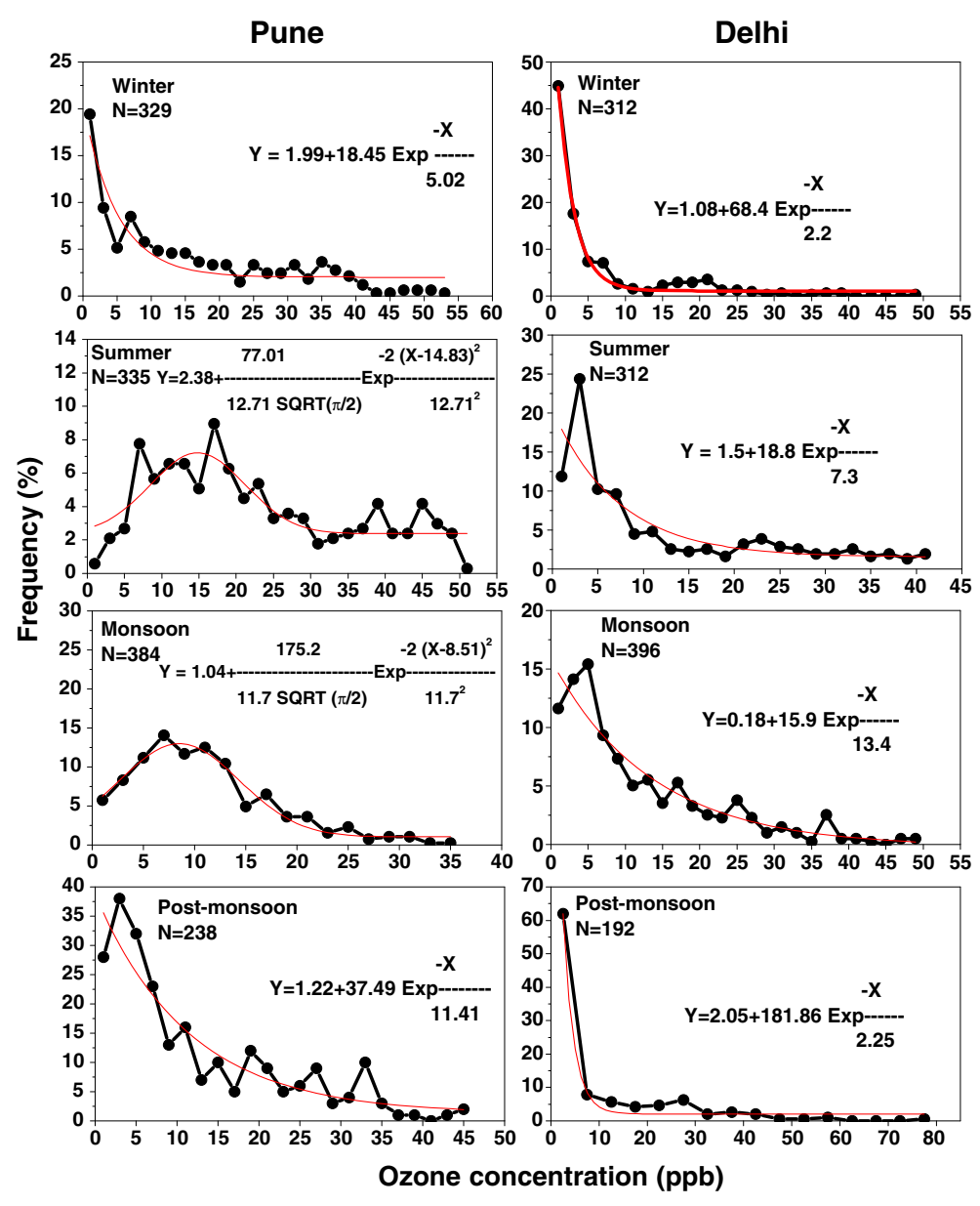

Figure 1. Seasonwise percentage frequency distribution of the concentration of surface ozone observed at Pune and Delhi during 1990-1999. 
Table 1. Summary of some statistical parameters in relation to ozone concentration at Pune and Delhi.

\begin{tabular}{|c|c|c|c|c|}
\hline Parameters & Winter & Summer & Monsoon & Post-monsoon \\
\hline \multicolumn{5}{|l|}{ Pune } \\
\hline Ozone concentration range corresponding to maximum frequency (ppb) & $0-5$ & $15-20$ & $5-10$ & $0-5$ \\
\hline Maximum frequency $(\%)$ & 19.4 & 8.9 & 14 & 38 \\
\hline Maximum ozone concentration (ppb) & 53 & 51 & 35 & 45 \\
\hline \multicolumn{5}{|l|}{ Delhi } \\
\hline Ozone concentration range corresponding to maximum frequency (ppb) & $0-5$ & $0-5$ & $0-5$ & $0-5$ \\
\hline Maximum frequency (\%) & 44.8 & 24.4 & 15.4 & 61.9 \\
\hline Maximum ozone concentration (ppb) & 49 & 41 & 49 & 77.5 \\
\hline
\end{tabular}

controlling this distribution pattern of the surface ozone concentration.

Based on observations and fitted distributions it may be stated that the maximum frequency of ozone occurrence during winter and post-monsoon seasons at Pune is in the concentration range of 0-5 ppb. During summer and monsoon seasons, it is in the range of $15-20 \mathrm{ppb}$ and $5-10 \mathrm{ppb}$, respectively. The percentage value of the maximum frequency during winter, summer, monsoon and post-monsoon seasons is $19.4 \%, 8.9 \%, 14 \%$ and $38 \%$ and the maximum concentration is $53,51,35$ and $45 \mathrm{ppb}$, respectively.

The distribution plot for Delhi shows that the frequency of ozone occurrence is maximum in the range of $0-5 \mathrm{ppb}$ for all the four seasons. The percentage value of the maximum frequency during winter, summer, monsoon and post-monsoon seasons is $44.8 \%, 24.4 \%, 15.4 \%$ and $61.9 \%$ and the maximum concentration is $49,41,49$ and $77.5 \mathrm{ppb}$, respectively. The above results are summarized in table 1 also.

\subsection{Time series analysis}

Time series analysis of surface ozone concentration at Pune and Delhi is made and is plotted in figure 2. It may be seen in the figure that, during the observational period, ozone concentration at both the locations is less during cold months and high during hot months when solar radiation reaching the ground surface is also high. This implies, in general, that the dominant factor controlling the concentration of ozone at both the locations is photochemistry. Trend analysis during the observational period indicates that annual average concentration of ozone is significantly decreasing at Pune $(r=-0.363$, significant at better than $0.01 \%)$. Average rate of decrease is estimated to be $1.54 \mathrm{ppb}$ per year. On the other hand, there is no trend whatsoever in the variation of surface ozone concentration at Delhi. The correlation coefficient $(r=0.089)$ of the trend at Delhi is insignificant.

\subsection{Diurnal variation of surface ozone at Pune and Delhi}

Figure 3 depicts average diurnal variation of surface ozone observed at Pune and Delhi during a 10year period from 1990 to1999. Vertical bars shown at individual hours of the day along the diurnal curve indicate standard deviation values of surface ozone concentration about the 10-year mean concentration at those hours. It is seen in the figure that the general trend of variation is same at both the locations. The concentration of surface ozone is less during night hours and more during day hours. Minimum value is recorded before sunrise. As the sun rises, concentration starts increasing, becomes maximum in the afternoon hours and starts decreasing afterwards. At both the locations, the concentration is minimum (6 ppb at Pune and $3.7 \mathrm{ppb}$ at Delhi) at $0600 \mathrm{hrs}$ IST, increases slowly up to $0800 \mathrm{hrs}$ IST and then increases at a faster rate to reach its peak value $(23.5 \mathrm{ppb}$ at Pune and $27 \mathrm{ppb}$ at Delhi) around 1400 hrs IST. Afterwards,

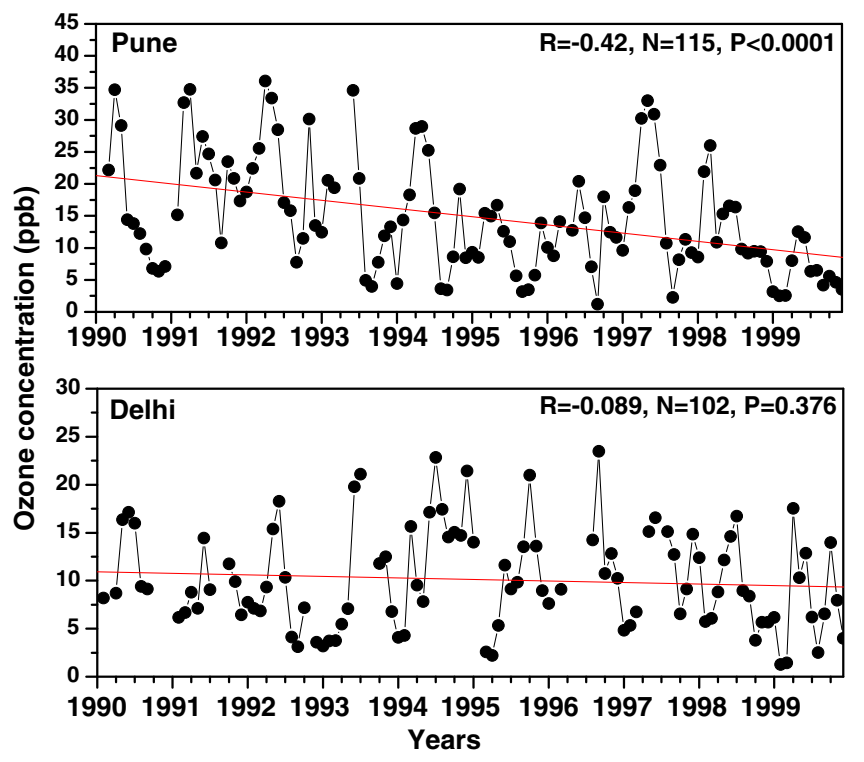

Figure 2. Surface ozone time series for Pune and Delhi during 1990-1999. 


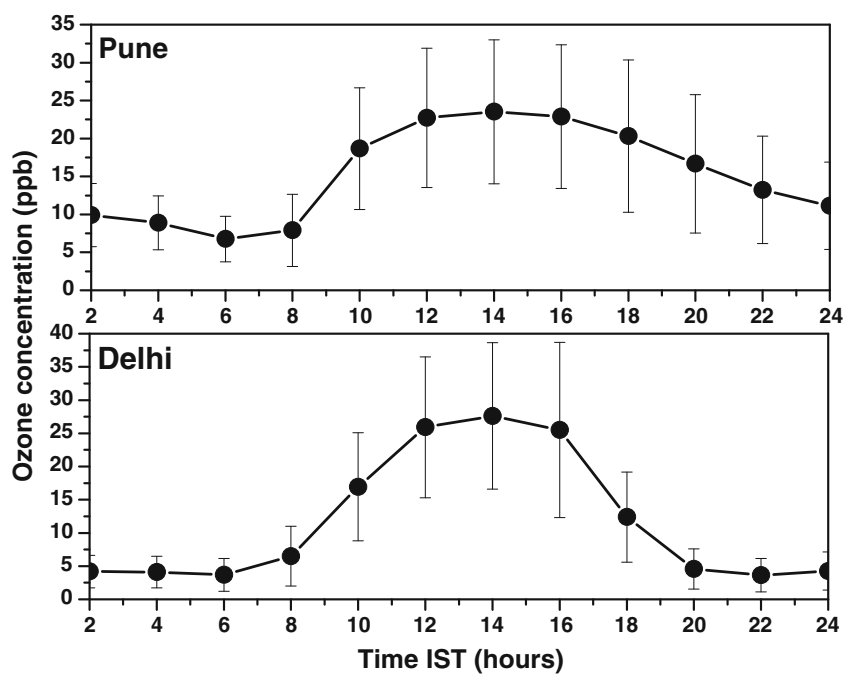

Figure 3. Diurnal variation of surface ozone at Pune and Delhi based on the data for the period from 1990 to 1999.

the concentration of surface ozone at Delhi starts decreasing first at slow rate and then at faster rate to attain an average value of $4.5 \mathrm{ppb}$ at $2000 \mathrm{hrs}$ IST. Further, there is little variation in the concentration of surface ozone over the rest period of the day. On the other hand, the concentration of surface ozone at Pune falls at slower rate than that at Delhi after the peak value and maintains the rate of fall in the concentration throughout the remaining period of the day. The observed diurnal variations of surface ozone are similar to the general trend of diurnal variations of temperature at the respective locations (IMD 1991, 2005). This implies that the surface ozone concentration has association with the temperature at both the locations.

\subsubsection{Seasonwise diurnal variation of surface ozone at Pune and Delhi}

Figure 4 shows diurnal variation of surface ozone at Pune (left hand side) and Delhi (right hand side) during four different seasons. It is observed from the figure that minimum surface ozone concentration at Pune reaches at $0600 \mathrm{hrs}$ IST in all the seasons except in winter season. Minimum concentration in winter is observed at $0800 \mathrm{hrs}$ IST. The minimum concentrations for winter, summer, monsoon and post-monsoon seasons are 3.6, 9.3, 6.7 and $4.6 \mathrm{ppb}$, respectively for Pune. In winter and

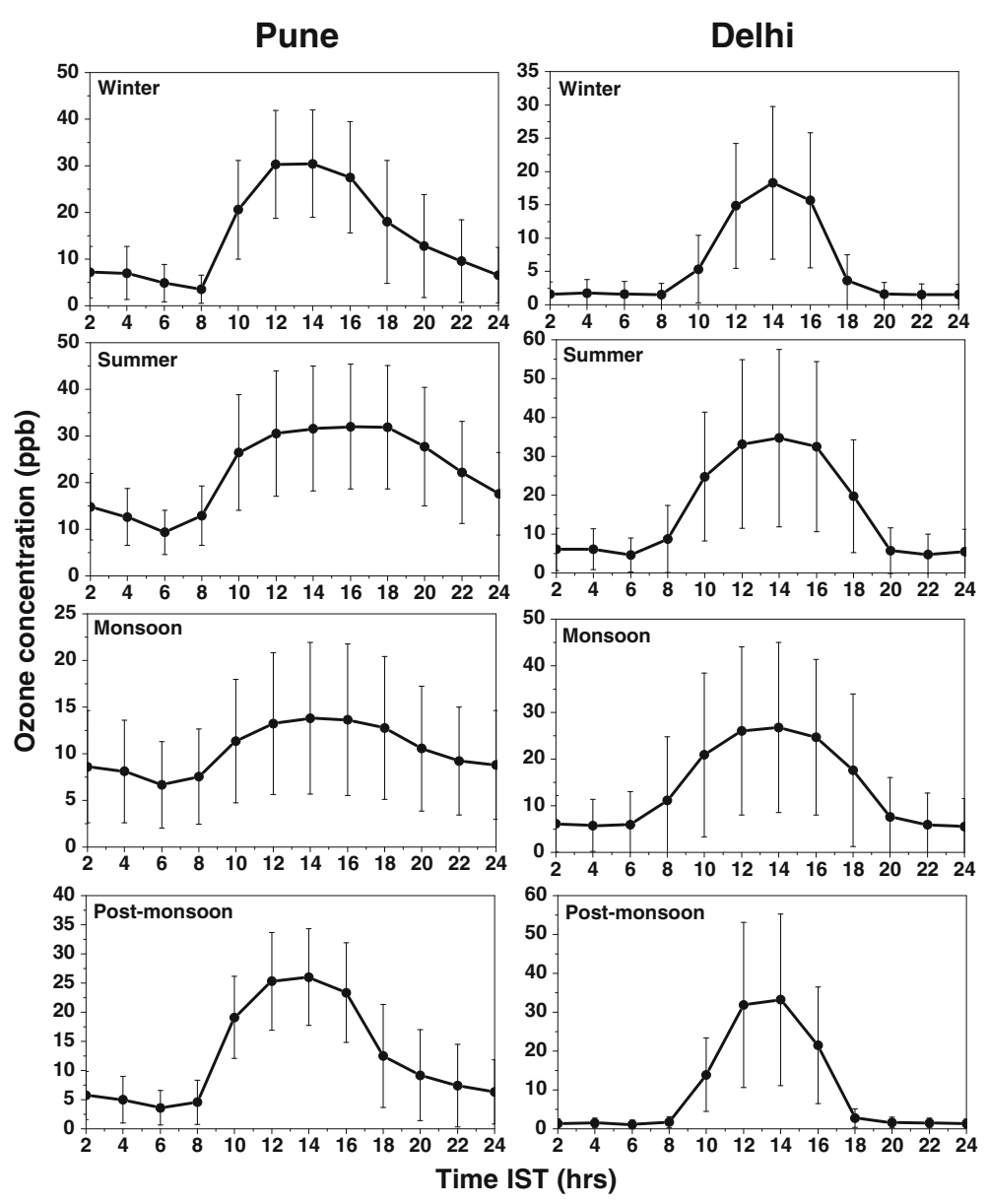

Figure 4. Diurnal variation of surface ozone at Pune and Delhi for four different seasons during the period from 1990 to 1999. 


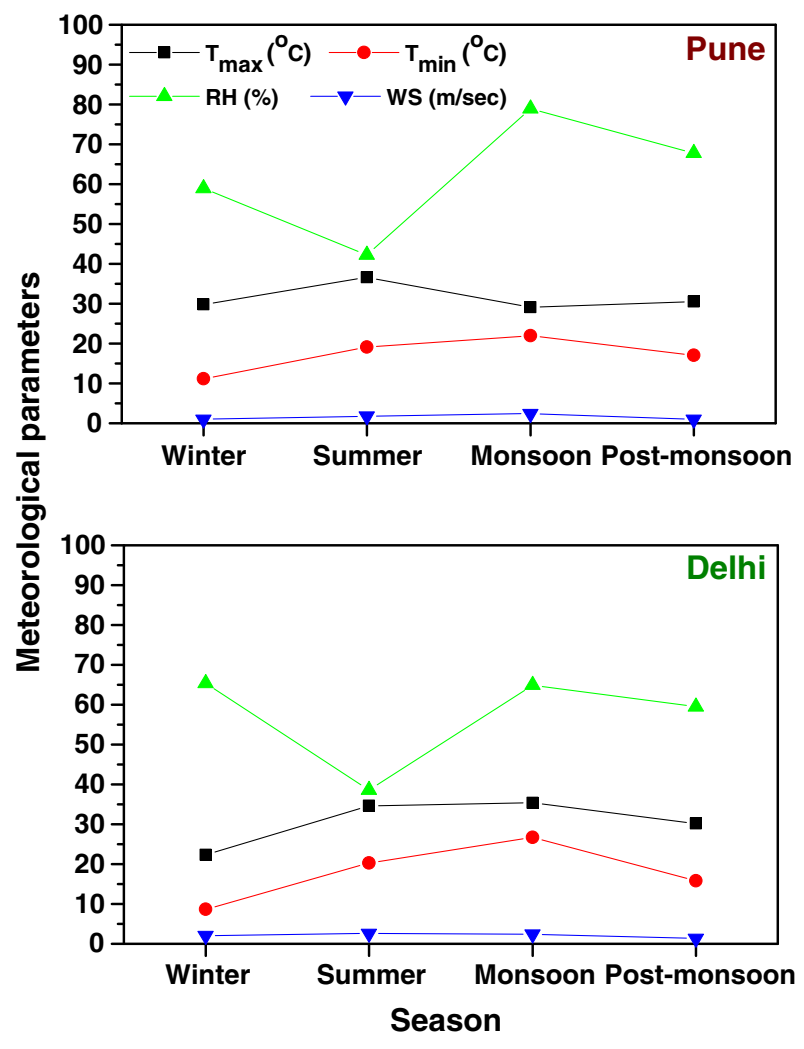

Figure 5. Seasonal variation of average maximum temperature, minimum temperature, relative humidity and wind speed at Pune and Delhi during 1990-1999.

post-monsoon seasons, rise in the concentration of surface ozone from minimum to maximum value is sharp and curves are more peaked than those in the other two seasons. This is mainly because nighttime depletion of surface ozone is more and length of sunshine hours providing favourable temperature condition to photochemical production of surface ozone is less during winter and post-monsoon seasons than those during other two seasons.

The effect of less sunshine hours during winter and post-monsoon seasons than that during summer season on comparatively sharp rate of increase in ozone concentration from minimum to maximum can be better understood by estimating seasonal mean ratio of difference between maximum and minimum temperatures to duration of sunshine hours $\left[\left(T_{\max }-T_{\min }\right) /\right.$ day hours $]$. It may be seen in figure 5 that difference between maximum and minimum temperatures in winter and summer seasons are nearly the same. Further, it is well known that duration of sunshine hours during winter is less than that during summer. Consequently, the ratio value for winter will be more than that for summer, which is due to less sunshine hours in winter than in summer. Similarly, the ratio value for post-monsoon season will also be more than that for summer. Thus the above ratio value, which is controlled mainly by sunshine hours during individual seasons, represents almost exactly the seasonal rate of increase of surface ozone concentration from its minimum value to maximum value. Basically, it is the distribution of incoming solar radiation and temperature over the sunshine hours at the location of interest which under the abundances of ozone precursors ensures the rate of increase or decrease of ozone concentration. The trend of diurnal variations of surface ozone for post-monsoon and winter seasons is very similar except during the time period range of 0600$0800 \mathrm{hrs}$ IST. This similarity is due to nearly similar temperature and humidity condition during the two seasons. The curves for summer and monsoon seasons are comparatively flat because the duration of maximum values in the afternoon hours is more due to persistence of favourable temperature condition for surface ozone production. Maximum concentration of surface ozone is recorded to be the highest $(32.0 \mathrm{ppb})$ in summer and the lowest (13.8 ppb) in monsoon season. Ranges of surface ozone concentration for winter, summer, monsoon and post-monsoon seasons are 3.6-30.5, 9.3-32.0, 6.7-13.8 and 4.6-26 ppb, respectively.

Seasonwise diurnal variation of surface ozone at Delhi shows that, in all the four seasons, surface ozone concentration remains nearly the same during the period from sunset to sunrise and is much less than the peak concentration observed during the day hours. The minimum concentration of surface ozone observed during winter, summer, monsoon and post-monsoon is 1.5, 4.7, 5.6 and $1.1 \mathrm{ppb}$, respectively. Rise in surface ozone concentration from minimum to maximum and fall thereafter from maximum to minimum is steeper during winter and post-monsoon seasons than those during summer and monsoon seasons. This is similar to that as seen in the case of seasonwise diurnal variation of surface ozone at Pune; and hence explanation for this also is based on the distribution of incoming solar radiation and temperature over the total length of the sunshine hours as given in the earlier paragraph (figure 5). In summer season, maximum concentration is highest (34.7 ppb) and its duration is also longer. The maximum concentration is seen to be lowest $(18.3 \mathrm{ppb})$ in winter season. The range of surface ozone concentration observed during winter, summer, monsoon and post-monsoon seasons at Delhi is 1.5-18.3, 4.734.7, 5.6-26.0 and 1.1-33.2 ppb, respectively. These observations for diurnal variation of surface ozone concentration over Pune and Delhi are summarized in table 2 . The above diurnal variations of surface ozone clearly indicate the impact of temperature on the production of surface ozone at Pune and Delhi. The minimum and the maximum surface ozone concentration levels observed at Pune 
Table 2. Seasonwise average concentration range observed in diurnal variation of surface ozone at Pune and Delhi.

\begin{tabular}{lcccc}
\hline & Winter & Summer & Monsoon & Post-monsoon \\
\hline Pune & $3.6-30.5$ & $9.3-32.0$ & $6.7-13.8$ & $4.6-26.0$ \\
Delhi & $1.5-18.3$ & $4.7-34.7$ & $5.6-26.0$ & $1.1-33.2$ \\
\hline
\end{tabular}

and Delhi during all the four seasons also reflect the influence of temperature on the surface ozone production.

\subsection{Relationship of surface ozone with maximum temperature, relative humidity and $\mathrm{NO}_{2}$}

Regression analysis between surface ozone concentration and maximum temperature, based on their monthly average values of the individual years during the period of observation, has been made for Pune and Delhi and the plots are shown in figure 6 . It may be seen in the figure that the surface ozone concentration and the maximum temperature are correlated positively with correlation coefficient $(r)$ equal to 0.46 for Pune and 0.51 for Delhi. Both these correlation coefficients, though small in magnitude, are highly significant (i.e., significant at more than $0.01 \%$ ). This implies that the temperature is significantly influencing the production of ozone and photochemistry is the dominant mechanism controlling the concentration level of ozone at Pune and Delhi.

Plots of regression analysis of surface ozone on relative humidity for Pune and Delhi are shown in figure 7 . As the relative humidity has been recorded at 0830 and $1730 \mathrm{hrs}$ IST for both the stations, there are two regression plots for each station. It is seen in the figure that, except for the case of

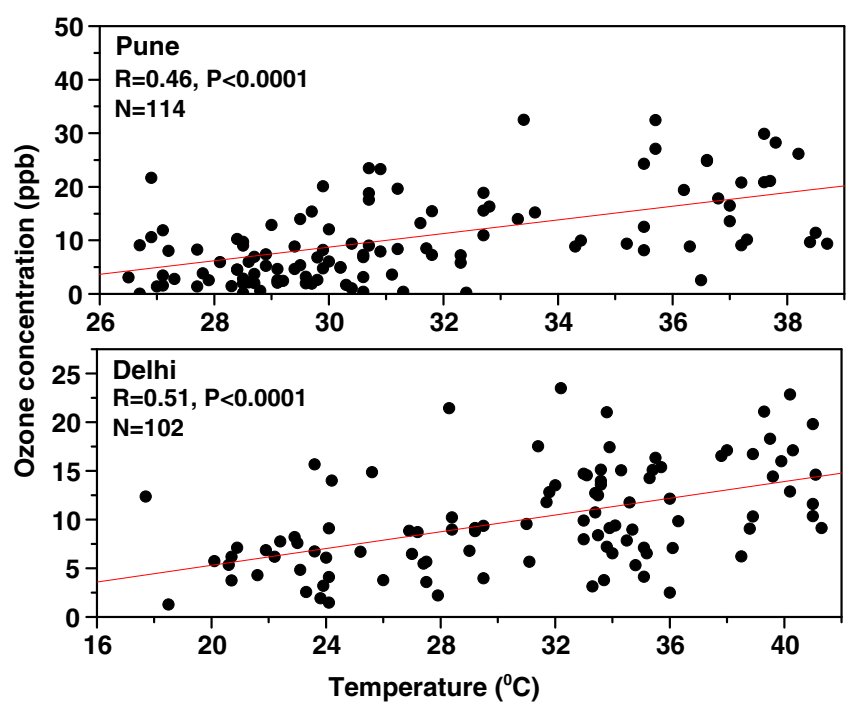

Figure 6. Relationship between surface ozone concentration and maximum temperature at Pune and Delhi during the period from 1990 to 1999.

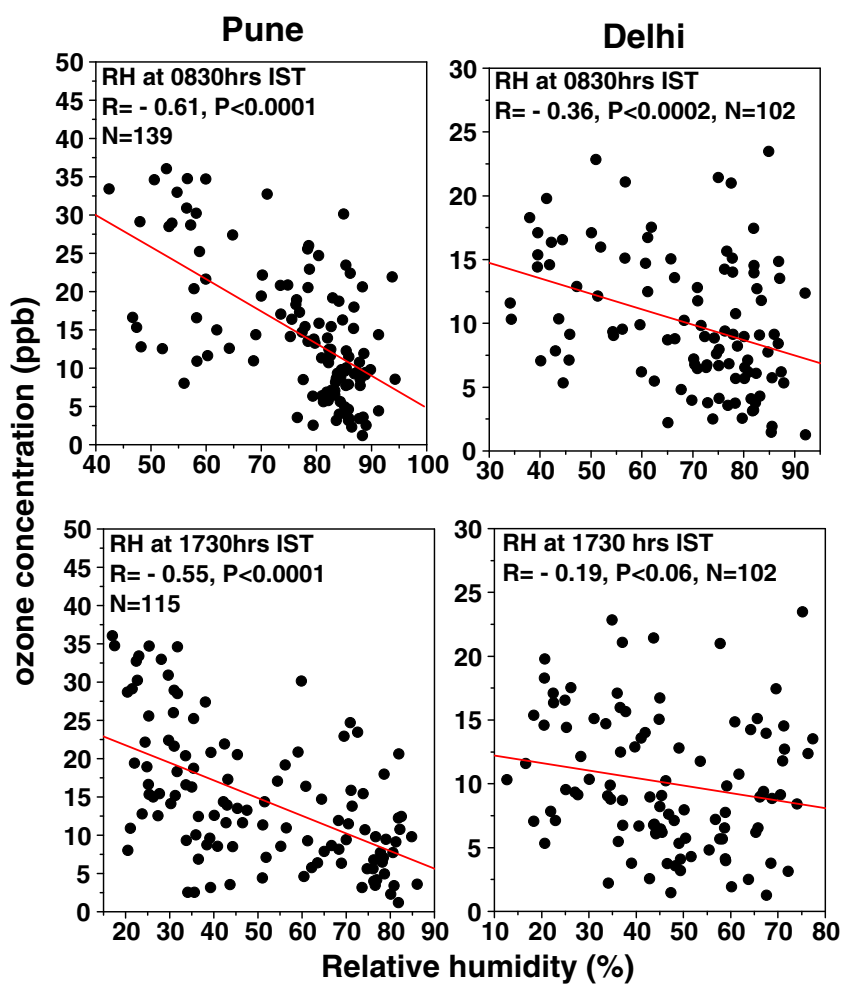

Figure 7. Relationship between surface ozone concentration and relative humidity at Pune and Delhi during the period from 1996 to 1999.

1730 hrs IST at Delhi, surface ozone is found to be highly negatively correlated with relative humidity. The correlation coefficients at 0830 and $1730 \mathrm{hrs}$ IST for Pune are -0.61 and -0.55 , respectively and that at $0830 \mathrm{hrs}$ IST for Delhi is -0.36 . The results are highly significant. Negative correlation between surface ozone and humidity lies in the fact that when humidity increases the major photochemical paths for removal of ozone (i.e., photolysis of ozone followed by the reaction of $\mathrm{O}\left({ }^{1} \mathrm{D}\right)$ with water vapour and reaction of $\mathrm{HO}_{2}$ with ozone) becomes effective. Secondly, higher humidity levels slow down photochemical process due to its association with greater cloud abundance, atmospheric instability and low incoming solar radiation. Also, the surface ozone is depleted through deposition of its molecules on water droplets (Londhe et al 2008).

Figure 8 presents regression plot of surface ozone on the tropospheric loading of nitrogen dioxide $\left(\mathrm{NO}_{2}\right)$. The figure indicates that both the parameters are positively correlated at Pune with correlation coefficient value equal to 0.35 (significant at $4 \%$ ). On the other hand, the relation of surface ozone with $\mathrm{NO}_{2}$ at Delhi is very weak. The positive relation of surface ozone with $\mathrm{NO}_{2}$ at Pune is justified as $\mathrm{NO}_{2}$ dissociates in the presence of solar energy to release oxygen atom which further combines with oxygen molecule to produce ozone. 


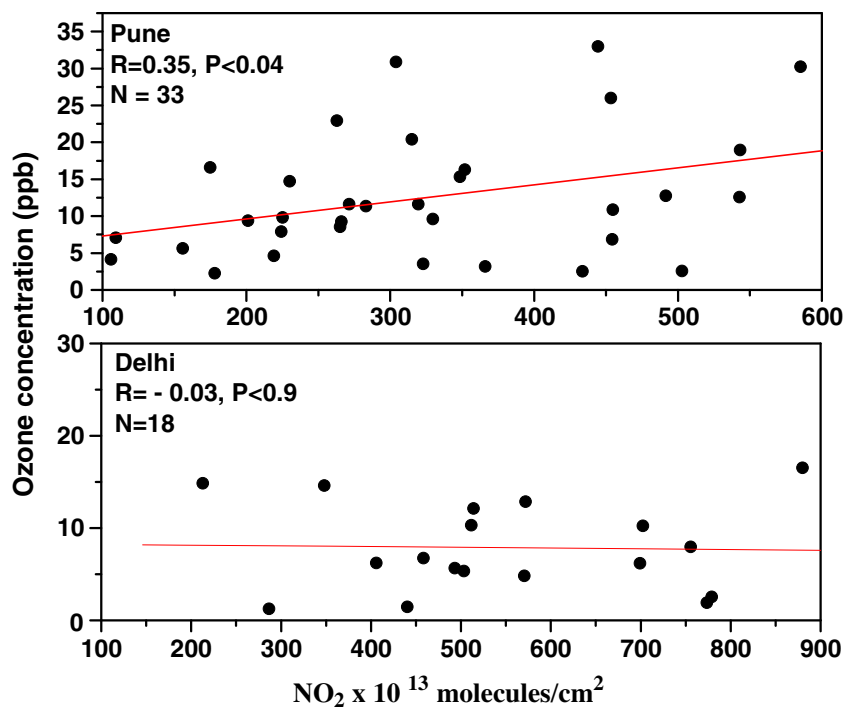

Figure 8. Relationship between columnar $\mathrm{NO}_{2}$ and surface ozone concentration at Pune and Delhi during the period from 1996 to 1999.
However, very weak relation as observed for Delhi needs further investigation.

\subsection{Long range transport of surface ozone and ozone precursors}

It has been shown in section 4.4 that correlation coefficients between ozone concentration and maximum temperature at both the locations are positive and small, though significant. This indicates that apart from photochemistry some other mechanism might also be significantly contributing to the observed concentration of ozone at these locations. The other effective mechanism may be long range transport of ozone and its precursor gases like $\mathrm{NO}_{\mathrm{x}}, \mathrm{CO}$ and HCs. The possibility of this mechanism is investigated on the basis of backward trajectory analysis, which is obtained from the NOAA Air Resources Laboratory's Hybrid Single Particle Lagrangian Integrated Model (HYSPLIT 4; see Real-time
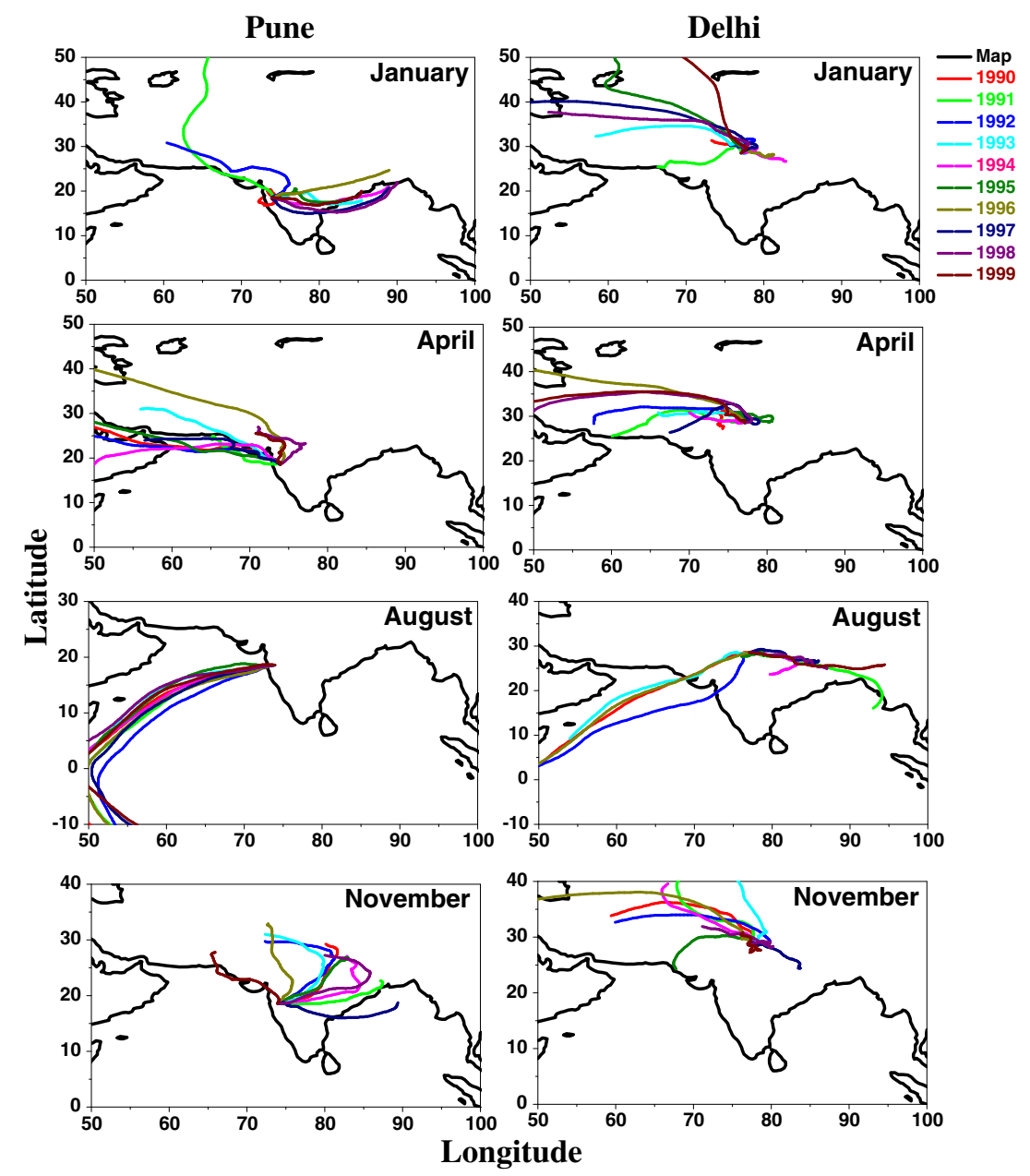

Figure 9. Five days' backward trajectories terminating on 5th of the selected months of the individual years during 19901999. (Note: January, April, August and November are considered as representative months for winter, summer, monsoon and post-monsoon seasons, respectively in the present study.) 
Environmental Application and Display System, http://www.arl.noaa.gov/ready.html). Figure 9 displays five days' backward trajectories for Pune and Delhi. These trajectories commence on 1st day of the months shown in the figure and end on 5 th day of the respective months. The months selected for trajectory plots are January, April, August and November which represent winter, summer, monsoon and post-monsoon seasons, respectively. Each plot of the figure contains 10 trajectories each specific to a year during 1990-1999. It may be seen in the figure that the prevailing winds at Pune and Delhi are either easterly to north-easterly or westerly to north-westerly in most of the months. It is only in the monsoon months when wind is approaching from southwest direction at Pune and from southwest and east to southeast directions at Delhi. Thus, the ambient winds reaching at Pune and Delhi in all the seasons, except in the monsoon season, are of continental origin passing through the source regions of pollutants. The prevailing wind during monsoon season at these locations is of marine origin and so may be relatively clean. It is quite possible that easterly to northeasterly or westerly to northwesterly continental winds may be bringing several anthropogenic species including ozone and its precursor gases from the distant sources. However, this possibility during the monsoon months is meager. Finally, it is concluded that transport mechanism may also be contributing, in general, to the total concentration of ozone at Pune and Delhi.

\section{Conclusions}

Surface ozone concentration data compiled for Pune and Delhi for a period of 10 years from 1990 to 1999 is analyzed in terms of its frequency distribution, annual trend, diurnal variation, and relationship with maximum temperature, relative humidity and $\mathrm{NO}_{2}$. Following broad conclusions are drawn from the analysis:

The surface ozone concentration range showing highest frequency of occurrence at Pune is $0-5 \mathrm{ppb}$ during winter and post-monsoon seasons and 1520 and 5-10 ppb during summer and monsoon seasons, respectively. It is $0-5 \mathrm{ppb}$ at Delhi during all the seasons.

On attempting to fit standard distribution to the observed frequency distributions of the surface ozone concentration, it is found that exponential decay of the first order fits well to the distributions observed during all the seasons at Delhi and during winter and post-monsoon seasons at Pune. The distributions observed at Pune during summer and monsoon seasons are represented by Gaussian distribution.
Time series analysis indicates that annual average concentration of ozone is significantly decreasing at Pune at the rate of $1.54 \mathrm{ppb} /$ year, whereas there is no trend whatsoever in the variation of surface ozone concentration at Delhi.

Diurnal variation of surface ozone at both the locations indicates that minimum value of surface ozone occurs before sunrise and maximum value in the afternoon hours.

Regression analyses of surface ozone with maximum temperature, relative humidity and $\mathrm{NO}_{2}$ at respective locations indicate that the surface ozone at these locations is mainly produced by photochemistry. When humidity increases the major photochemical paths for removal of ozone becomes effective and also the photochemical ozone production rate slows down. Backward trajectory analysis indicates that apart from photochemistry, long range transport of ozone and its precursor gases like $\mathrm{NO}_{\mathrm{x}}, \mathrm{CO}$ and $\mathrm{HCs}$ may also be contributing to the total concentration of ozone at Pune and Delhi.

\section{Acknowledgements}

The authors are deeply indebted to Prof. B N Goswami, Director, Indian Institute of Tropical Meteorology, Pune for providing support and guidance to carry out this work. Thanks are also due to India Meteorological Department for providing surface ozone and meteorological data.

\section{References}

Ali K, Momin G A, Safai P D, Chate D M and Rao P S P 2004 Surface ozone measurement over Himalayan region and Delhi, North India; Indian J. Rad. Space Phys. 33 391-398.

Ali K, Beig G, Chate D M, Momin G A, Sahu S K and Safai P D 2009 Sink mechanism for significantly low level of ozone over the Arabian Sea during monsoon; J. Geophys. Res. 114 D17306, doi: 10.1029/2008JD011256.

Beig G and Ali K 2006 Behavior of boundary layer ozone and its precursors over a great alluvial plain of the world: Indo-Gangetic Plains; Geophys. Res. Lett. 33 L24813, doi: 10.1029/2006GL028352.

Beig G, Ghude S D, Polade S D and Tyagi B 2008 Threshold exceedances and cumulative ozone exposure indices at tropical suburban site; Geophys. Res. Lett. 35 L02802, doi: 10.1029/2007GL031434.

Chatterjee R N, Prakash P and Ali K 1993 Lognormal distribution of the heights of convective clouds around Delhi, North India; J. Meteorol. 18 161-166.

Crutzen P J 1988 Tropospheric ozone: An overview; In: Tropospheric ozone (ed.) Isaksen I S A (Dordrecht: Reidel), pp. $3-32$.

Ganguly N D 2009 Surface ozone pollution during the festival of Diwali, New Delhi, India; e-Journal Earth Sci. India 2(IV) 224-229.

Graedel T E and Crutzen P J 1993 In: Atmospheric Change, An Earth System Perspective (New York: W H Freeman and Company), pp. 149-153. 
IMD Publication 1991 Climate of Haryana and Union Territories of Delhi and Chandigarh; In: State Climatological Summaries, PDGM 126/300-1991 (DSK. II), 98p.

IMD Publication 1995 Surface ozone recorder; I.S.C. No. 103.

IMD Publication 2005 Climate of Maharashtra.

Jain S L, Arya B C, Kumar A, Ghude S D and Kulkarni P S 2005 Observational study of surface ozone at New Delhi India; Int. J. Remote Sens. 26(16) 3515-3526, doi: 1080/01431160500076616.

Kelly N A, Wolf G T and Ferman M A 1984 Sources and sinks of ozone in rural areas; Atmos. Environ. 18 1251-1266.

Kuntasal G and Chang T Y 1987 Trends and relationships of $\mathrm{O}_{3}, \mathrm{NO}_{\mathrm{x}}$ and $\mathrm{HC}$ the south coast air basin of California; J. Air Pollut. Control Assoc. 37 1158-1163.

Lal S, Sahu L K, Gupta S, Srivastava S, Modh K S, Venkataramani S and Rajesh T A 2008 Emission characteristic of ozone related trace gases at a semi-urban site in the Indo-Gangetic plain using inter-correlations; J. Atmos. Chem. 60 189-204, doi: 10.1007/s10874-0089115-0.

Lippmann M 1991 Health effects of tropospheric ozone; Environ. Sci. Technol. Note 25(12) 1954-1962.

Liu S C, Trainer M, Fehsenfeld F C and Parrish D D 1987 Ozone production in the rural troposphere and the implications for regional and global ozone distributions; J. Geophys. Res. 92 4191-4207, doi: 10.1029/ JD092iD04p04191.

Londhe A L, Jadhav D B, Buchunde P S and Kartha M J 2008 Surface ozone variability in the urban and nearby rural locations of tropical India; Curr. Sci. 95(12) 1724-1729.

Nishanth T and Kumar M K S 2011 Diurnal variation of surface ozone with meteorological parameters at Kannur, India; Adv. Appl. Sci. Res. 2(3) 407-417.

Penkett S A 1984 Ozone increase in ground-level European air; Nature 311 14-15.

Purkait N N, De S, Sen S and Chakrabarty D K 2009 Surface ozone and its precursors at two sites in the northeast coast of India; Indian J. Rad. Space Phys. 38 86-97.

Reddy R R, Gopal K R, Reddy L S S, Narasimhulu K, Ahmmed Y N and Rao T V R 2008 Surface ozone measurements at Anantapur (AP), India; Indian J. Rad. Space Phys. 37 209-215.

Reich P B and Lassoie J P 1985 Influence of low concentrations of ozone on growth, biomass partitioning and leaf senescence in young hybrid poplar plants; Environ. Pollut. Sr. A 39 39-51.

Roy S, Beig G and Jacob D 2008 Seasonal distribution of ozone and its precursors over the tropical Indian region using regional chemistry-transport model; J. Geophys. Res. 113 D21307, doi: 10.1029/2007JD009712.

Sillman S and Samson P J 1995 Impact of temperature on oxidant photochemistry in urban, polluted rural and remote environments; J. Geophys. Res. 100 11,94711,508 .

Singh A, Sarin S M, Shanmugam P, Sharma N, Attri A K and Jain V K 1997 Ozone distribution in the urban environment of Delhi during winter months; Atmos. Environ. 31 3421-3427.

Sreedharan C R and Tiwari V S 1971 The use of Brewer 'bubbler' as a continuous surface ozone sensor; J. Phys. E: Sci. Instr. 4 706-707.

Steiner A L, Davis A J, Sillman S, Owen R C, Michalak A M and Fiore A M 2010 Observed suppression of ozone formation at extremely high temperatures due to chemical and biophysical feedbacks; PNAS 10(46) 19,685-19,690.

Valente R J and Thornton F C 1993 Emission of NO from soil at a rural site in central Tennessee; J. Geophys. Res. $982917-2925$.

Volz A and Kley D 1988 Evaluation of the Montsouris series of ozone measurements made in the nineteenth century; Nature 332 240-242.

Vukovich F M 1994 Boundary layer ozone variations in the eastern United States and their association with meteorological variations: Long term variations; J. Geophys. Res. 99(D8) 16,839-16,850.

Vukovich F M and Sherwell J 2003 An examination of the relationship between certain meteorological parameters and surface ozone variations in the BaltimoreWashington corridor; Atmos. Environ. 37 971-981.

Walcek C J and Yuan H H 1995 Calculated influence of temperature-related factors on ozone formation rates in the lower troposphere; J. Earth Syst. Sci. 34 1056-1069. 